\title{
Mineral phase in shell repair of Manila clam Venerupis philippinarum affected by brown ring disease
}

\author{
Nolwenn Trinkler ${ }^{1}$, Jean-François Bardeau ${ }^{2}$, Frédéric Marin ${ }^{3,4}$, Maylis Labonne ${ }^{5, *}$, \\ Aurélie Jolivet ${ }^{6}{ }$ Philippe Crassous $^{6}{ }^{6}$, Christine Paillard ${ }^{1}$ \\ ${ }^{1}$ IUEM, LEMAR, UMR CNRS/UBO/IRD 6539, Technopole Brest Iroise, 29280 Plouzané, France \\ ${ }^{2}$ LPEC, UMR CNRS 6087, Université du Maine, 72085 Le Mans Cedex 9, France \\ ${ }^{3}$ UMR CNRS 5561 Biogéosciences, Dijon, France \\ ${ }^{4}$ Université de Bourgogne, 6 Boulevard Gabriel, 21000 Dijon, France \\ ${ }^{5}$ IRD, LEMAR, UMR CNRS/UBO/IRD 6539, Centre IRD Bretagne, BP 70, 29280 Plouzané, France \\ ${ }^{6}$ Ifremer, STH, Z.I. Pointe du diable, BP 70, 29280 Plouzané, France
}

\begin{abstract}
The mineral phase of shell repair in the Manila clam Venerupis philippinarum affected by brown ring disease (BRD) was characterised at various scales and at various stages of shell repair by confocal Raman microspectrometry and scanning electron microscopy. Spherulitic and quadrangular aragonite microstructures associated with polyene pigments were clearly observed. Von Kossa staining showed that at the beginning of shell repair, hemocytes are filled with insoluble calcium carbonate salts in all fluids and then are transported toward the extrapallial fluids and the repair sites. Our analyses suggest that after a Vibrio tapetis attack and BRD deposit some clams rapidly cover the deposit, resulting in a modification in the microstructure, which could be produced by the participation of both the mantle and hemocytes.
\end{abstract}

KEY WORDS: Aragonite $\cdot$ Hemocytes $\cdot$ Shell microstructure $\cdot$ Calcium carbonate $\cdot$ Biomineralization $\cdot$ Mollusc $\cdot$ Raman microspectrometry $\cdot$ Scanning electron microscopy

Resale or republication not permitted without written consent of the publisher

\section{INTRODUCTION}

In marine biota, invertebrates are constantly exposed to external environmental insults. These insults can be of physicochemical nature, such as desiccation, exposure to UV light or accidental cracks, or of biological nature, such as predation or competition for space. During evolution, a majority of sedentary invertebrates have acquired the capacity to develop a mineralised exoskeleton to protect themselves against such occurrences. In addition, their exoskeleton supports their soft bodies (Simkiss \& Wilbur 1989). In molluscs, the protective exoskeleton is the shell, which is mainly composed of calcium carbonate. The calcium carbonate layers of molluscan shells can be formed by aragonitic crystals such as in the clam Mercenaria mercenaria (Taylor et al. 1973), by calcitic crystals such as in the oyster Crassostrea virginica (Carriker 1996) or by a mix of the 2 crystal polymorphs such as in the abalone Haliotis rufescens (Nakahara et al. 1982). In exceptional environmental conditions the highly unstable vaterite can also be formed (Spann et al. 2010).

The Manila clam Venerupis philippinarum is a heterodont bivalve of economic importance. Its valves are constructed by the superimposition of 2 aragonitic layers (Taylor et al. 1973). The inner layer is described as 'homogeneous' while the outer layer is a 'composite prismatic' structure (Boggild 1930, Shimamoto 1986). As in other Venerideae, the attachment of the mantle to the shell along the pallial line separates the extrapallial space into 2 compartments, which contain the central and the peripheral extrapallial fluids (Allam \& Paillard 1998, Gosling 2003).

In Europe, this clam is regularly affected by a pathology named brown ring disease (BRD). This disease, which is characterised by the presence of a brown deposit on the inner surface of the valves, is caused by the bacterium Vibrio tapetis (Paillard \& Maes 1990). This disease was first recognized in 1987 when mass mortalities of cultured Manila clams were recorded in Landeda, north Finistère (Brittany, France) (Paillard et 
al. 1989, Flassch et al. 1992). Landeda was the first Manila clam production site in France (Paillard et al. 1989, Flassch et al. 1992).

Vibrio tapetis colonises the periostracum and inhibits the normal process of shell biomineralisation. The external response of the clam to the bacterial attack consists of a secretion of a brown organic matrix on the inner face of the shell, the well-known 'brown ring'. Immunological or PCR studies on the different physiological fluids of the clam have shown that, at later stages of the infection, $V$. tapetis invades the circulatory system (hemolymph) and the extrapallial fluids (Allam 1998, Allam et al. 2002, Paillard et al. 2006). At this advanced stage, clams often die from a hemolymphatic septicaemia. In some cases, clams recover by secreting a white shell layer on the brown organic matrix (Paillard \& Maes 1995a,b). The bulk organic matrix associated with the shell repair has been recently characterised using Raman microspectrometry, wavelength-dispersive spectrometry (WDS) microprobe analysis and organic matrix quantification (Trinkler et al. 2009, 2010a). However, the mineral phase and the microstructure of repaired Manila clam shells, including those that exhibit a fully repaired shell, have not yet been studied. In the present study, experimental investigations have been performed on the microstructure and the nature of the calcium carbonate repair layer, using Raman microspectrometry and scanning electron microscopy (SEM). In particular, Raman microspectrometry, a nondestructive and noninvasive technique, provides qualitative and quantitative information on organomineral composites (Urmos et al. 1991, Kontoyannis \& Vagenas 2000, Withnall et al. 2003, Hedegaard et al. 2006, Carteret et al. 2009). A complementary characterisation using the Von Kossa stain, which is a stain specific for insoluble calcium salts, was performed on hemolymph and extrapallial fluids, revealing the presence of these salts in hemocytes. These techniques applied to BRD-affected and nonBRD-affected clams provide valuable information on the mineral phase.

\section{MATERIALS AND METHODS}

Origin of clams and BRD characterization. Adult Manila clams (25 to $35 \mathrm{~mm}$ ) used for Raman microspectrometry and Von Kossa stain were collected in field at the Landeda site on 23 April 2007. Most of them exhibited a brown ring (Paillard \& Maes 1994). Juvenile clam specimens (10 to $16 \mathrm{~mm}$ ) used for Raman microspectrometry and SEM were provided by the Satmar nursery, Marennes, France, on 3 May 2007 (Table 1). Shells were systematically opened, emptied of soft tissue by means of a scalpel and rinsed with tap water before determining the stage of BRD on the inner face of the valves using binocular stereomicroscopy. The shell repair stages (SRS) were determined according to previous studies, which identified 5 stages (Paillard \& Maes 1994, Paillard 2004). Stage 0 corresponds to a brown deposit without repair. Stage 1 corresponds to the apposition of calcified points. The partial covering of the deposit by wide calcified plates corresponds to Stage 2. Stage 2.5 corresponds to an almost complete repair. In Stage 3, the brown deposit is completely covered by a fully calcified layer (Fig. 1).

RAMAN microspectrometry. Raman microspectrometer: We used a Raman microspectrometer (T64000, Horiba-Jobin-Yvon) equipped with a confocal system, a motorized $x-y$ stage and a coherent spectrum argon/ krypton ion laser emitting at $51435 \mathrm{~nm}$. The laser was focused onto the sample using a microscope equipped with a $100 \times$ objective; the resulting spatial resolution was about $1 \mu \mathrm{m}$. The scattered light was then analysed using a single monochromator ( 600 gratings $\mathrm{mm}^{-1}$ ), coupled to a nitrogen-cooled charge-coupled device (CCD) de-

Table 1. Venerupis philippinarum. Information on clams used for Raman microspectrometery, scanning electron microscopy (SEM) and Von Kossa staining. BRD: brown ring disease; SRS: shell repair stage

\begin{tabular}{|c|c|c|c|c|}
\hline Sample & Origin & $\begin{array}{l}\text { Injected with } \\
\text { Vibrio tapetis? }\end{array}$ & BRD-affected? & Size $(\mathrm{mm})$ \\
\hline \multicolumn{5}{|c|}{ Raman microspectrometry } \\
\hline 3 adults (A1, A2) & Landeda & No & NonBRD-affected & $25-35$ \\
\hline 5 juveniles (J1, J2, J3) & Satmar Nursery & No & NonBRD-affected & $10-16$ \\
\hline 12 adults & Landeda & No & BRD-affected: 2 SRS 0, 2 SRS 1, 1 SRS 2, 7 SRS 3 & $25-35$ \\
\hline \multicolumn{5}{|l|}{ SEM } \\
\hline 2 juveniles & Satmar Nursery & No & NonBRD-affected & $10-16$ \\
\hline 10 juveniles & Satmar Nursery & Yes & $\begin{array}{l}\text { BRD-affected: } 2 \text { SRS 0, } 2 \text { SRS 1, } 2 \text { SRS 2, } \\
\text { 2 SRS 2.5, } 2 \text { SRS } 3\end{array}$ & $10-16$ \\
\hline \multicolumn{5}{|l|}{ Von Kossa stain } \\
\hline 9 adults & Landeda & No & NonBRD-affected & $25-35$ \\
\hline 21 adults & Landeda & No & $\begin{array}{l}\text { BRD-affected: } 1 \text { SRS } 0,1 \text { SRS 1, } 14 \text { SRS } 2 \text {, } \\
2 \text { SRS } 2.5,3 \text { SRS } 3\end{array}$ & $25-35$ \\
\hline
\end{tabular}



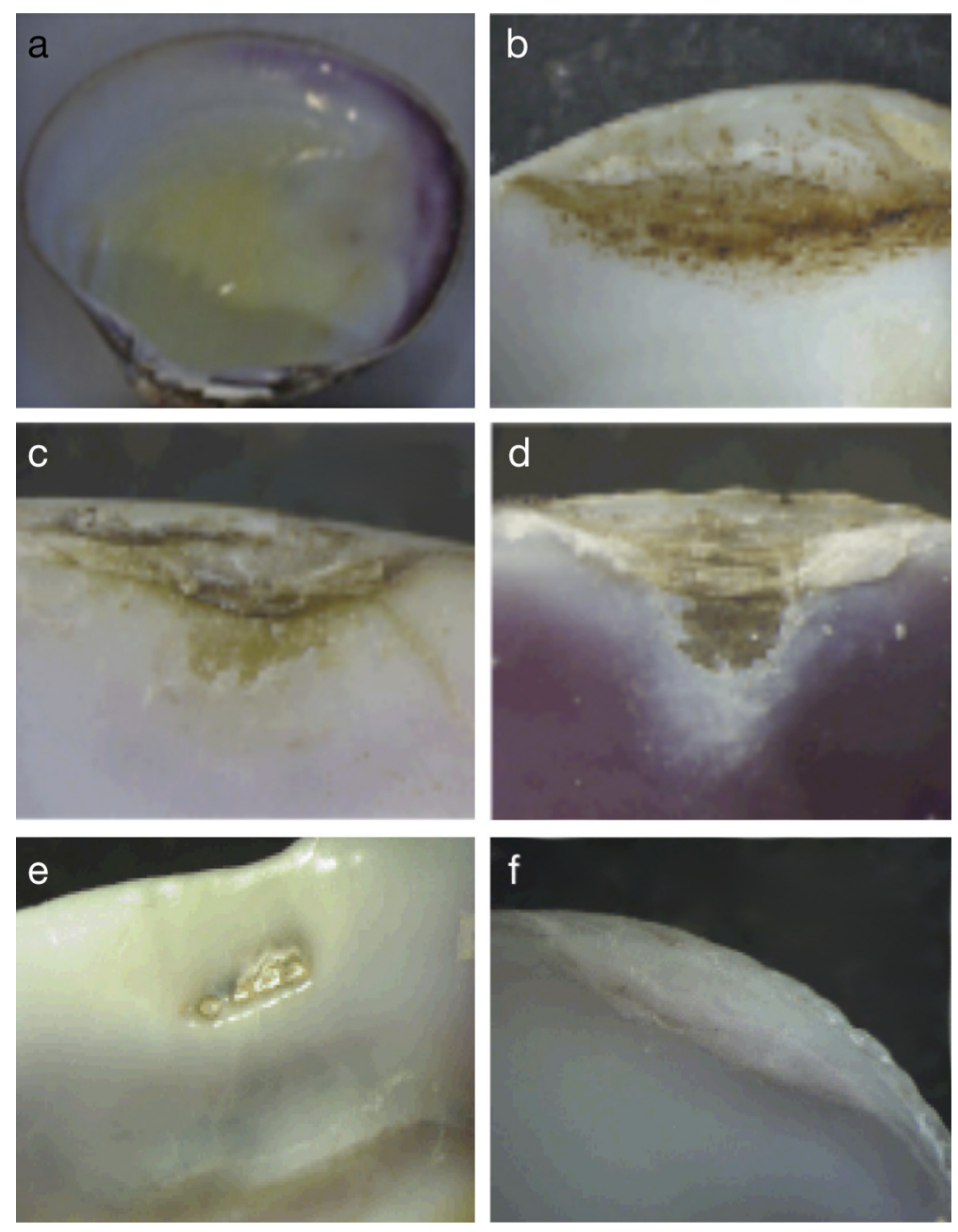

Fig. 1. Venerupis philippinarum. Examples of the shell repair stages (SRS) of the Manila clam after a BRD infection (Querne 2005). Descriptions of SRS are as follows: (a) nonBRD-affected clam, homogenous inner layer; (b) SRS 0, dark (brown) deposit without repair; (c) SRS 1, dark (brown) deposit with points of repair; (d) SRS 2, dark (brown) deposit with plates of repair; (e) SRS 2.5, almost total repair; (f) SRS 3, total repair tector. For each sample, parameters were adjusted as follows: laser power (varying from 30 to $50 \mathrm{~mW}$ ), spectra accumulation (from 2 to 30 times) and exposure time (from 1 to $60 \mathrm{~s}$ ) (Table 2). Measurements were systematically made at $2 \mu \mathrm{m}$ depth and sometimes on fresh breaks to avoid surface contamination. Reported Raman spectra were normalised by dividing intensity by acquisition time (s) and laser power (mW). The peak positions and the relative integrated intensities of identifiable vibrational bands and luminescence were determined using the LABSPEC software.

Samples analyzed using Raman microspectrometry: Raman analysis was first carried out on the internal surface of a nonBRD-affected adult (A1) in 5 regions of the right valve: central zone, peripheral anterior zone, peripheral posterior zone, peripheral ventral zone and siphonal zone. Raman spectra were also acquired on the internal surface of 4 nonBRD-affected juveniles (Table 1). Similar results were obtained with the 4 shells so only 2 of them are presented (see Fig. 4; J1, left valve, peripheral ventral zone; J2, left valve, central zone). In addition, we compared the spectra obtained from the inner and the outer shell layers from 2 nonBRD-affected shells (one adult, A2, and one juvenile, J3) after having cut both of them with cutting pliers to avoid aragonite/calcite thermal transformation (Table 1).

Subsequently, we studied adult clams affected by BRD. For each SRS, analyses were made on the shell surface to characterise the evolution of the Raman signal

Table 2. Venerupis philippinarum. Samples and parameters used for Raman microspectrometry analysis. A: adult; J: juvenile

\begin{tabular}{|c|c|c|c|c|}
\hline \multirow{2}{*}{ Sample } & \multirow{2}{*}{ Analysis } & \multicolumn{3}{|c|}{ Parameter } \\
\hline & & Acquisition time (s) & Laser power (mW) & Accumulation (times) \\
\hline A1 & Surface analysis & $30-50$ & 30 & $2-4$ \\
\hline J1 & & 35 & 30 & 2 \\
\hline $\mathrm{J} 2$ & & 50 & 30 & 2 \\
\hline 2 clams SRS 0 & & 1 & 30 & 10 \\
\hline 2 clams SRS 1 & & 1 & 30 & $10-30$ \\
\hline 1 clam SRS 2 & & 2 & 30 & 30 \\
\hline 2 clams SRS 3 & & 4 & 30 & 30 \\
\hline A2 & Edge analysis & 40 & 30 & 2 \\
\hline J3 & & $30-40$ & 50 & 2 \\
\hline 1 nonBRD-affected adult & Polyene analysis & $30-60$ & 50 & 2 \\
\hline 5 SRS 3 adults & & $2-50$ & $30-40$ & $2-10$ \\
\hline
\end{tabular}


during the shell repair ( 2 clams with SRS 0, 2 with SRS 1, 1 with SRS 2 and 2 with SRS 3; Table 1).

SEM analysis. Inoculation: Vibrio tapetis CECT 4600, isolated from Venerupis philippinarum in Landeda (Paillard \& Maes 1990), was grown in marine agar (1 1 distilled water, $15 \mathrm{~g}$ pastagar [AES Chemunex], $30 \mathrm{~g}$ sea salts [Sigma], $4 \mathrm{~g}$ peptone [AES Chemunex], $1 \mathrm{~g}$ yeast extract [AES Chemunex] and $0.1 \mathrm{~g} \mathrm{Fe}\left(\mathrm{PO}_{4}\right)_{2}$ [Merck]) at $18^{\circ} \mathrm{C}$ for $72 \mathrm{~h}$ before inoculation. Then, $V$. tapetis was resuspended in sterile sea water (SSW).

Two hundred juvenile clams, obtained from a low susceptibility stock at the Satmar farm (Trinkler et al. 2010b), were injected in the pallial cavity with $0.05 \mathrm{ml}$ of SSW and 200 other clams (same stock) with $0.05 \mathrm{ml}$ of a solution containing Vibrio tapetis at $2 \times 10^{8}$ cells $\mathrm{ml}^{-1}$ as previously described (Paillard \& Maes 1990). The clams were maintained in marine aquaria at $14^{\circ} \mathrm{C}$. A low susceptibility stock of clams was chosen for their capacity to repair their shell (a higher SRS) (Trinkler et al. 2010b). After $6 \mathrm{wk}$, clams were sampled and their SRS was characterised (Fig. 1).

Sample preparation for SEM: Using a QUANTA 200 SEM (FEI), observations were made on the inner valve surface of both nonBRD-affected shells that were not injected and experimentally diseased shells. The outer layer was visible on the edge of the shell. BRD-affected and nonBRD-affected zones were cut out with a scalpel. Fragments from 2 shells of nonBRD-affected clams and from 2 shells of each SRS $(0,1,2,2.5$ and 3$)$ were soaked in $70 \%$ ethanol for $2 \mathrm{~h}$, rinsed with distilled water and dried at $37^{\circ} \mathrm{C}$ (Table 1). Then, non BRD-affected and repaired fragments were soaked in sodium hypochlorite solution $(0.027 \%$ active chlorine for $2 \mathrm{~h}$ ) to remove the organic phase and isolate the mineral phase. As the brown deposit is entirely organic (Trinkler et al. 2010a,b), clams at SRS 0 were not soaked in sodium hypochlorite solution. The fragments were rinsed with distilled water, dried at $37^{\circ} \mathrm{C}$ and glued onto SEM stubs with conductive silver paint and coated with gold, using a cathodic spray SCD 040 (Blazers Union).

Von Kossa stain. Fluids collection: The hemolymph, the peripheral extrapallial fluid (PEF) and the central extrapallial fluid (CEF) were collected from 30 adult clams from which SRS was also characterised: 9 nonBRD-affected, 1 SRS 0, 1 SRS 1, 14 SRS 2, 2 SRS 2.5 and 3 SRS 3 (as described in Fig. 1 and Table 1). The hemolymph was collected from the posterior adductor muscle sinus with a $1 \mathrm{ml}$ hypodermic syringe (25 gauge needle) through the ligament at the base of the umbo (Oubella et al. 1993). Extrapallial fluids were collected by slipping a 21 gauge needle attached to a $1 \mathrm{ml}$ syringe between the shell and the mantle after the valves were opened by cutting the adductor muscles. This allowed the pallial fluid to drain away as described in Allam \& Paillard (1998). PEF was collected from the pallial muscle and the sinus, and CEF from the mantle, in the central compartment between the pallial line and the subarticular compartment.

Fluids were individually centrifuged with a cytospin slide centrifuge $(28 \times g, 10 \mathrm{~min})$ onto glass slides to achieve hemocyte monolayers $(150 \mu \mathrm{l}$ of fluid per glass slide). Three glass slides per sample and per fluid type were made when it was possible. Glass slides were airdried and stored in the dark.

Von Kossa staining: The Von Kossa method stains insoluble salts of calcium phosphate and calcium carbonate. The staining was performed according to the following standard procedure (Gabe 1968): $10 \mathrm{~min}$ incubation in $5 \%(\mathrm{w} / \mathrm{v})$ of silver nitrate in water in the dark, $2 \times 10$ min washes with distilled water to remove the excess silver nitrate, staining with $0.5 \%$ $(\mathrm{w} / \mathrm{v})$ of hydroquinone in water for $2 \mathrm{~min}$ in daylight, a wash with distilled water (10 $\mathrm{min})$, an incubation with sodium thiosulfate $(5 \%, \mathrm{w} / \mathrm{v})$ in water for $30 \mathrm{~s}$, a wash with distilled water (10 min) and a brief immersion $(15 \mathrm{~s})$ in aniline blue $(3 \% \mathrm{w} / \mathrm{v})$ in water. Samples were dehydrated $(10 \mathrm{~min}$ in $70 \%$ ethanol, $10 \mathrm{~min}$ in $95 \%$ ethanol and $2 \times 10 \mathrm{~min}$ in $100 \%$ ethanol) and mounted with a mounting medium (Eukitt). The CEF of a clam at SRS 3 was also soaked in acetic acid $(0.1 \mathrm{M}, 10 \mathrm{~min})$ to evaluate the specificity of the stain (salts of calcium phosphate and calcium carbonate are dissolved with acetic acid). Then all the slices were observed and photographed with an inverted optical microscope (DM IRB, Leica). The intensity of the staining was visually assessed.

\section{RESULTS}

\section{Raman micro-spectrometry results}

\section{NonBRD-affected clams}

Raman spectra measured on the inner layer of different valve zones of a nonBRD-affected adult clam were compared (Fig. 2). In the 155 to $1460 \mathrm{~cm}^{-1}$ wave number range, the Raman spectra measured on the surface of the nonBRD-affected adult clam (A1) were similar in all zones of the valve, and the strong bands observed at $155,205,271,704,1087$ and $1460 \mathrm{~cm}^{-1}$ were assigned to the aragonite phase. In the 1018 to $4071 \mathrm{~cm}^{-1}$ wave number range, well-defined bands appeared in the posterior and siphon zones (Table 3). Two particular bands, named R1 (around 1100 to $1140 \mathrm{~cm}^{-1}$ ) and R4 (around 1500 to $1525 \mathrm{~cm}^{-1}$ ) were attributed to carboncarbon single and double bond stretching vibrations, respectively. The observation of these bands revealed the presence of polyene pigments (Table 3, Fig. 3). 
Raman spectra of the inner layers of non-BRDaffected adult and juvenile clam shells are shown in Fig. 4. Raman spectra acquired on the surface of nonBRD-affected juvenile clams (J1 and J2) showed the presence of aragonite and polyenes bands and a strong luminescence. In the juvenile spectra (J1, J2), the luminescence intensity was systematically higher than in the adult (A1). In juvenile clam shells, the series of polyene bands were also more difficult to observe because the peaks were of much lower intensity (which is related to the concentration of pigment) and/or were masked by the luminescence of the sample.

Finally, Raman spectra measured on the inner and outer layers of nonBRD-affected adult and juvenile clam shells are compared in Fig. 5. Raman spectra acquired on the edge of a juvenile (J3) and of an adult (A2) specimen, showed well-defined vibrational bands attributed to aragonite and polyenes. Furthermore, the adult outer layer exhibited higher luminescence intensity than did its inner layer. The juvenile outer layer presented lower luminescence intensity than did its inner counterpart (Fig. 5). The luminescence intensity observed in the juvenile inner layer was higher than in the adult inner layer. Finally, the luminescence intensities of the juvenile and adult clam outer layers were similar (J3 and A2, Fig. 5).
BRD-affected clams

Raman spectra acquired on the brown deposits at different SRS are shown in Fig. 6. At SRS 0, before repair, a high-luminescence signal was observed. During the process of shell repair (from SRS 1 to SRS 3), the main aragonite bands (usually observed between 158 and $1087 \mathrm{~cm}^{-1}$ ) became more prominent. At the end of the repair process (SRS 3), polyene bands also reappeared in the wave number range 1037 to $4091 \mathrm{~cm}^{-1}$.

Thus, the aragonite bands were always observed in nonBRD-affected adult and juvenile shells as well as in repaired shell and not in organic brown rings. Similarly, the polyene bands were observed in nonBRD-affected and repaired clams but never in the brown rings (Fig. 6).

\section{SEM results}

\section{NonBRD-affected clams}

The internal shell surfaces of nonBRD-affected clams were observed by SEM. The inner layer was composed of organised, flattened and imbricate crystals embedded in a thin organic layer (Fig. 7a). After a surface treatment with sodium hypochlorite, the thin organic

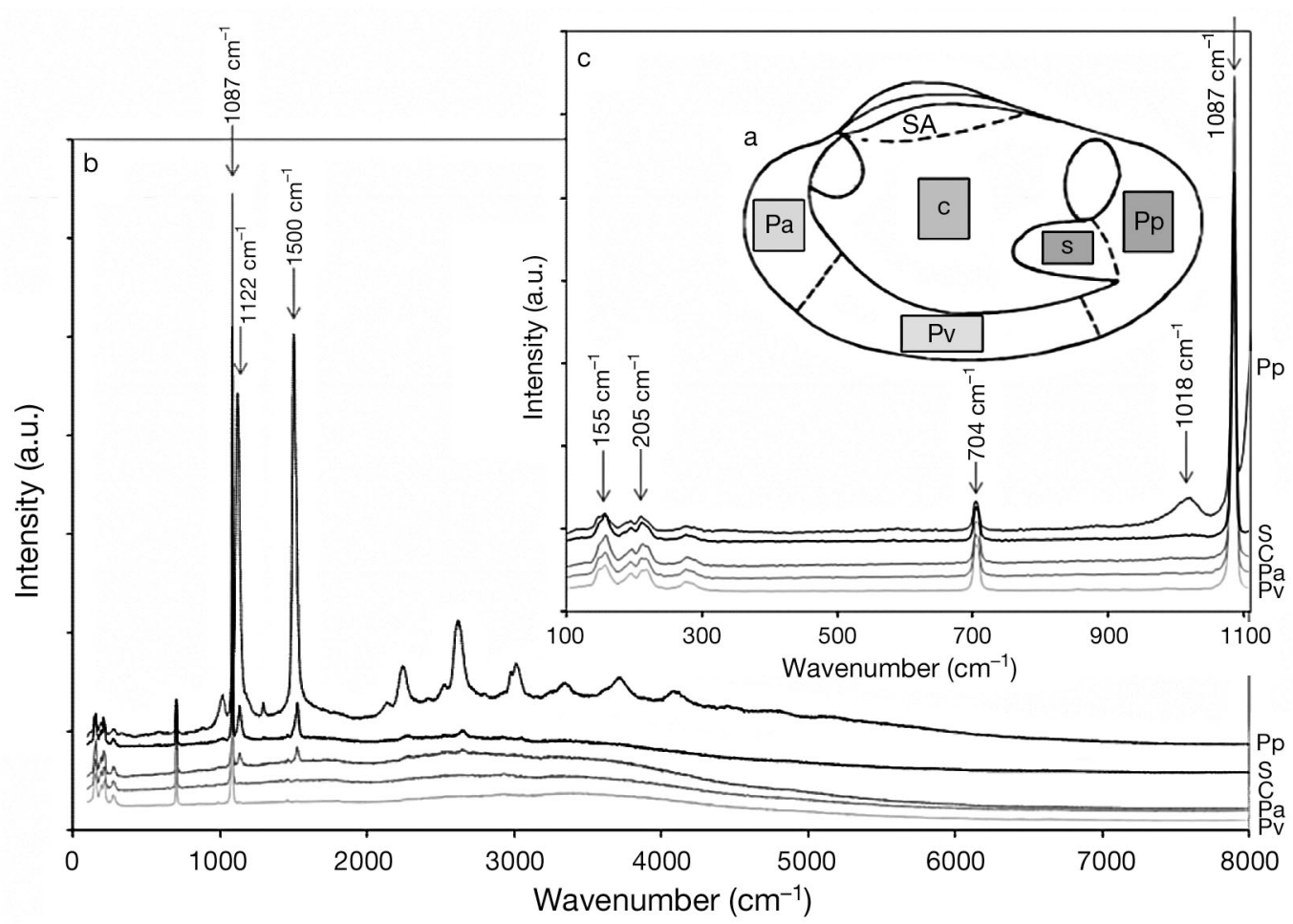

Fig. 2. Venerupis philippinarum. (a) Zones of the inner surface of the Manila clam shell (right valve). (b) Raman spectra acquired on surface of a nonBRD-affected adult (A1) shell in different regions. C: central zone; Pa: peripheral anterior zone; Pp: peripheral posterior zone; Pv: peripheral ventral zone; S: siphon zone; SA: subarticulation zone. (c) Enlargement of low wave number ( $\mathrm{cm}^{-1}$ ) (1/wavelength). The baselines are vertically shifted to facilitate comparison. a.u.: arbitrary unit (intensity normalised by dividing intensity by acquisition time [s] and the laser power [mW]) 
Table 3. Venerupis philippinarum. Wave numbers of pigment bands on clam shell $\left(\mathrm{cm}^{-1}\right)$. R1 designates wave numbers for carbon-carbon single bond stretching vibration and R4 designates wave numbers for carbon-carbon double bond stretching vibration. H: nonBRD-affected; SRS 3: total shell repair

\begin{tabular}{|c|c|c|c|}
\hline Clam status & Example plot & $\mathrm{R} 1$ & $\mathrm{R} 4$ \\
\hline \multicolumn{4}{|l|}{ Inner layer } \\
\hline H Adult & Fig. 2 A1 ${ }^{\mathrm{a}}$ & 1122 & 1500 \\
\hline H Juvenile & Fig. 4 J1 & 1135 & 1527 \\
\hline H Juvenile & Fig. 4 J2 & 1136 & 1530 \\
\hline H Adult & Fig. 5 A2 & 1139 & 1530 \\
\hline H Juvenile & Fig. 5 J3 & 1121 & 1501 \\
\hline H Adult & & 1136 & 1529 \\
\hline Adult SRS3 & Fig. 6 & 1126 & 1505 \\
\hline Adult SRS3 & & 1139 & 1531 \\
\hline Adult SRS3 & & 1127 & 1511 \\
\hline Adult SRS3 & & 1123 & 1511 \\
\hline Adult SRS3 & & 1127 & 1506 \\
\hline \multicolumn{4}{|l|}{ Outer layer } \\
\hline Adult & Fig. 5 A2 & 1135 & 1530 \\
\hline Juvenile & Fig. 5 J3 & 1117 & 1497 \\
\hline \multicolumn{4}{|c|}{$\begin{array}{l}\text { ather pigment bands for A1: 1018, 1122, 1166, 1291, } \\
\text { 1500, 2130, 2241,2411,2502, 2609, 2787, 2975, 3009, } \\
3311,3681 \text { and } 4071 \mathrm{~cm}^{-1}\end{array}$} \\
\hline
\end{tabular}

layer disappeared (Fig. 7b). In the case of the outer layer (visible at the edge of the shell), the calcium crystals formed mounds, like prisms, in surface view (Fig. 7c).

\section{BRD-affected clams}

At the beginning of the BRD process, the brown deposits appeared on the internal shell surface. SEM

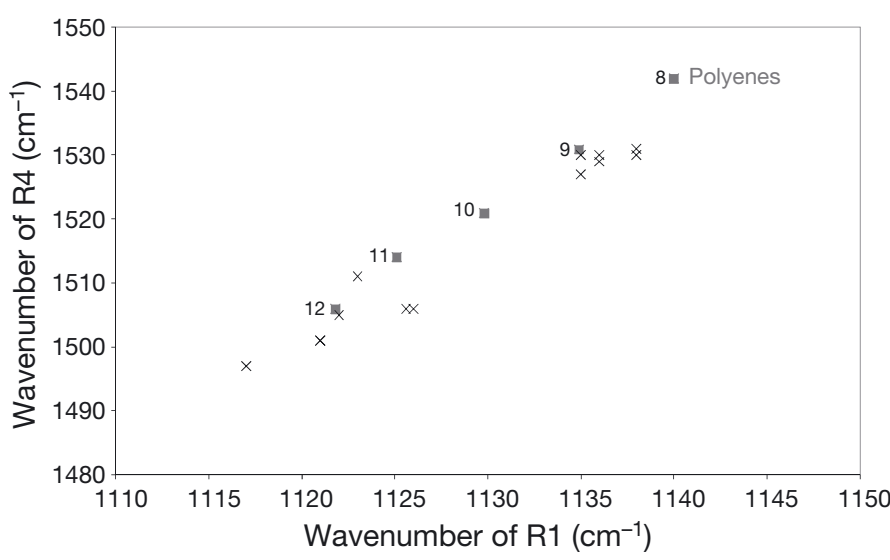

Fig. 3. Venerupis philippinarum. R1: wave numbers $\left(\mathrm{cm}^{-1}\right)$ (1/wavelength) of carbon-carbon single bond stretching vibration plotted against R4: wave numbers of carbon-carbon double bond stretching vibration. $\times$ : $V$. philippinarum samples reported in Table $3 ; \square$ : predicted Raman shift of resonantly coupled modes for polyenes with different chain lengths reported by Hedegaard et al. (2006)

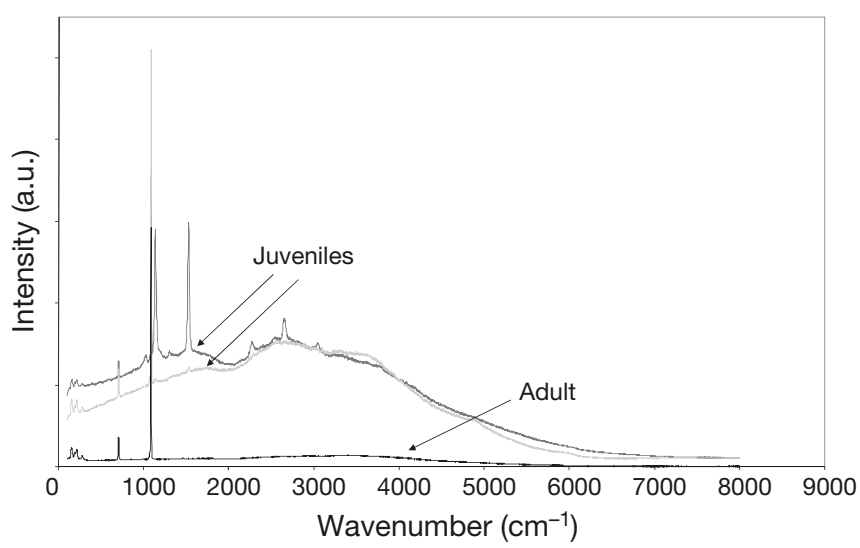

Fig. 4. Venerupis philippinarum. Raman spectra acquired on surface of inner layer of nonBRD-affected clam shells of one adult A1 (ventral zone, dark spectrum) and 2 juveniles J1 (ventral zone, grey spectrum) and J2 (central zone, dark grey spectrum). Baselines are vertically shifted to facilitate comparison. Wavenumber $\left(\mathrm{cm}^{-1}\right)$ : 1/wavelength; a.u.: arbitrary unit (intensity normalised by dividing intensity by acquisition time [s] and the laser power $[\mathrm{mW}])$. The dome-like curves (juveniles) correspond to the intrinsic luminescence

observations showed that they consisted of a thick organic layer, laid down on the inner shell layer (Fig. 7d). From SRS 1 to SRS 2.5, SEM results showed that calcium carbonate minerals were progressively settled on the brown deposit until the affected zone was almost entirely covered (Fig. 7e-o). At SRS 1, in shells not treated with sodium hypochlorite, minerals seemed to be partially masked under a thick organic matrix, which looked like the BRD organic matrix (Fig. 7e). After sodium hypochlorite treatment, we noticed a great variability of microstructures in SRS 1, from rounded 'spherulitic-like' (Fig. 7f) to rectangular (Fig. $7 \mathrm{~g}$ ). In treated fragments, the rectangular minerals were surrounded by a thin organic matrix, and as the sodium hypochlorite treatment degraded this matrix it formed holes (Fig. 7g). During SRS 2, 2.5 and 3, with treatment, spherulitic-like (Fig. 7h,i,l) and rectangular (Fig. 7o) microstructures were also observed. From SRS 1 to SRS 2.5, calcium carbonate minerals were not well organized.

At SRS 2.5, an organic layer appeared and partially covered the calcium carbonate crystal mounds (Fig. $7 \mathrm{j}, \mathrm{k}$ ). At the end of the shell repair (SRS 3), this organic layer entirely covered the crystals (Fig. $7 \mathrm{~m}$ ). It was thick, bright and smooth (Fig. 7j,k,m) and appeared different from the organic matrix of the nonBRD-affected inner layer and from the brown deposit (Fig. 7d). Under the BRD-organic layer, calcium carbonate minerals exhibited an organisation similar to that observed from SRS 1 to SRS 2.5, in particular, rectangular structures were evident (Fig. $7 g, 0$ ). 


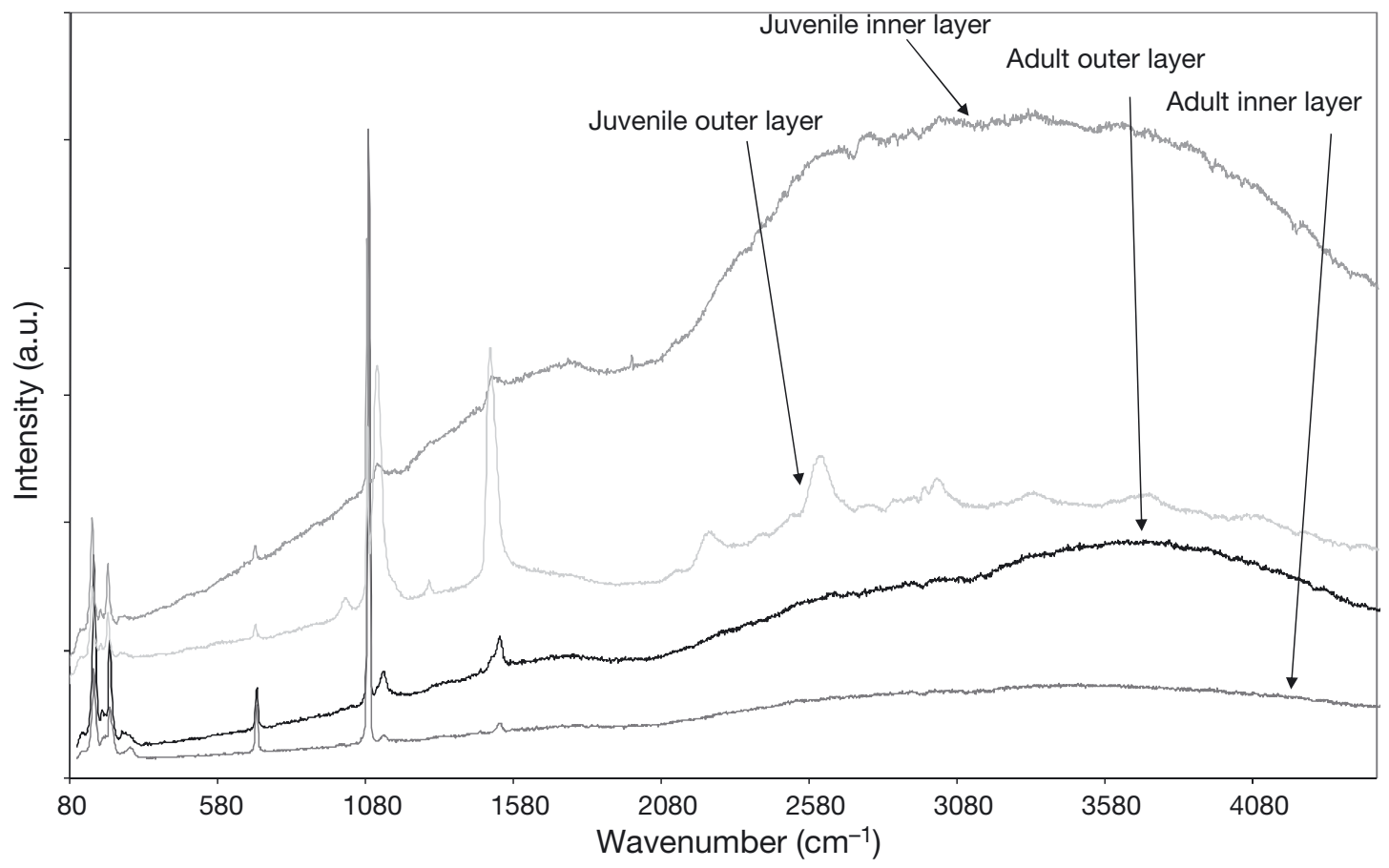

Fig. 5. Venerupis philippinarum. Raman spectra acquired on the edge of nonBRD-affected clam shells of one adult A2 and one juvenile J3 to measure the signatures of inner and outer layers. Baselines are shifted vertically to facilitate comparison. Note that the juveniles exhibit high luminescence. Wavenumber $\left(\mathrm{cm}^{-1}\right)$ : 1/wavelength; a.u.: arbitrary unit (intensity normalised by dividing intensity by acquisition time $[\mathrm{s}]$ and the laser power $[\mathrm{mW}])$

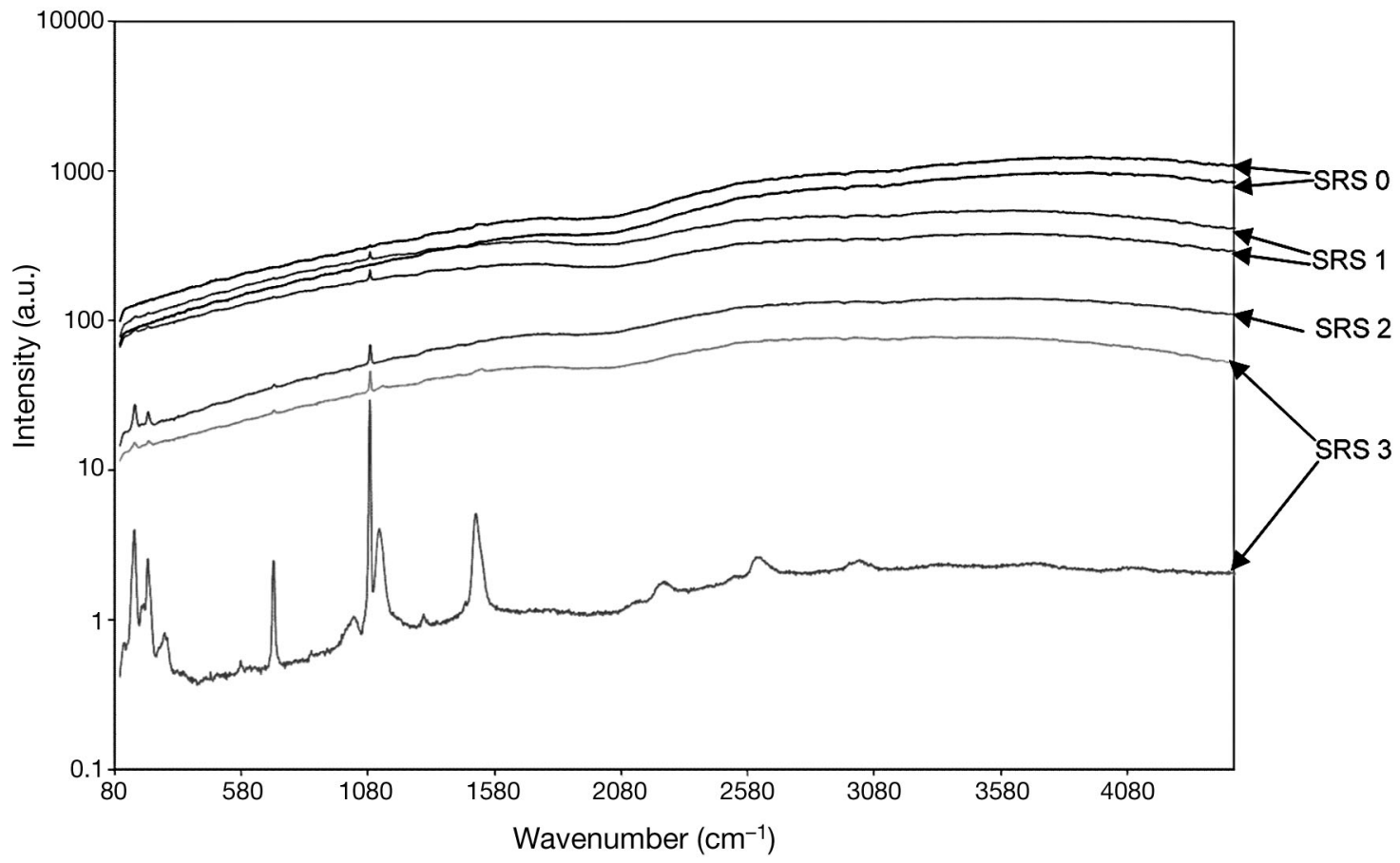

Fig. 6. Venerupis philippinarum. Raman spectra acquired on the surface of 7 samples of Manila clams, with different shell repair stages (SRS). SRS 0: disease without repair; SRS 1: calcified points; SRS 2: calcified plates; SRS 3: total shell repair. Baselines are not shifted vertically. Wavenumber $\left(\mathrm{cm}^{-1}\right)$ : 1/wavelength; a.u.: arbitrary unit (intensity normalised by dividing intensity by acquisition time [s] and the laser power [mW]) 

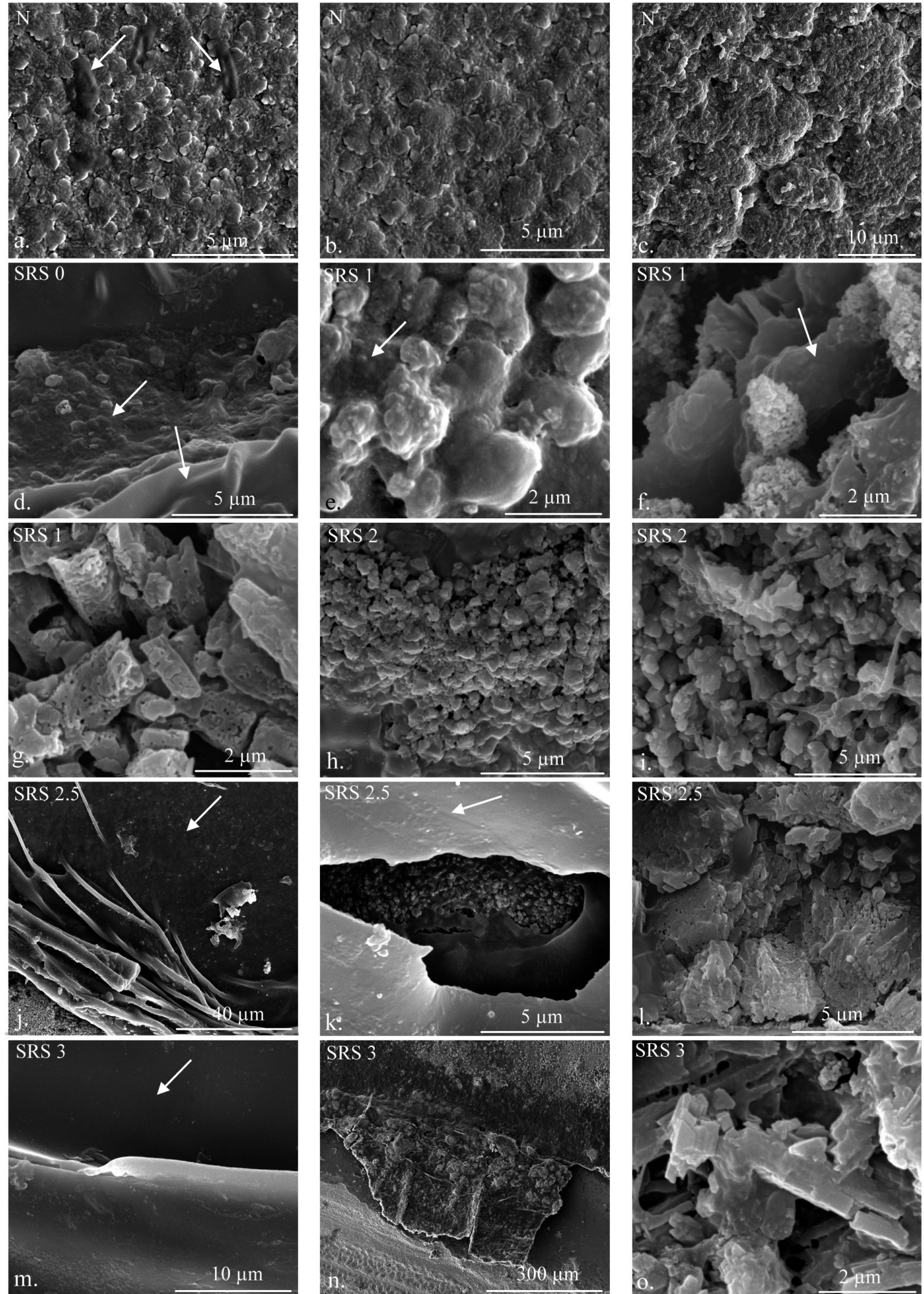

Fig. 7. Venerupis philippinarum. SEM views of the inner surface of Manila clam shells. NonBRD-affected and experimentally diseased shells were observed to describe the development of the microstructure during the shell repair mechanism. (a,b) NonBRD-affected (N) inner layer. (c) NonBRD-affected outer layer. (d) Brown deposit without shell repair, i.e. shell repair stage (SRS) 0. (e-g) SRS 1. (h,i) SRS 2. (j-l) SRS 2.5. (m-o) SRS 3. Shells in (7b,f,g,i,l,n,o) were soaked in sodium hypochlorite solution $(0.027 \%$ of active chlorine) for $2 \mathrm{~h}$. Arrows indicate organic matrices 


\section{Von Kossa staining}

In all clams, some hemocytes on each glass slide were coloured with Von Kossa stain whatever the conditions and the compartments, but the proportion of stained hemocytes and the intensity of the brown staining varied depending on the nature of the sampled fluid (hemolymph, CEF, PEF) and on the repair stage (Fig. 8, Table 4). The brown intensity of the staining and the proportion of stained hemocytes on each slide were visually assessed. In each case, the localisation of the staining in hemocytes seemed concentrated in vesicles and more diffused in cytoplasm. The results are summarised in Table 4. In nonBRD-affected clams, the proportion of stained hemocytes was lower in hemolymph than in both extrapallial fluids, but the intensity of the staining was lower in the CEF than in the hemolymph and in the PEF (Fig. 8a-c, Table 4). At SRS 1, the proportion of stained hemocytes increased in hemolymph and the brown intensity increased in CEF (Fig. 8d-f, Table 4). At SRS 2, the proportion of stained hemocytes and the brown intensity drastically decreased in hemolymph. At the same time, the proportion of stained hemocytes increased in both extrapallial fluids, similarly to the staining intensity (Fig. $8 g-i$, Table 4). At SRS 2.5, the proportion of stained hemocytes and the brown intensity increased in the hemolymph and reached a higher level than that recorded for nonBRD-affected hemolymph. At the same time, the brown intensity decreased slightly in both extrapallial fluids (Fig. 8j-1, Table 4). During this stage, the proportion of stained hemocytes and the brown intensity were high or very high in hemolymph and both extrapallial fluids (Fig. 8j-1, Table 4). At the end of the shell repair (SRS 3), the situation was similar to SRS 2.5, with the exception that the proportion of stained hemocytes and the brown intensity decreased slightly in hemolymph, where it was moderate and intermediate, respectively, similar to the level found in nonBRD-affected hemolymph (Fig. 8m-o, Table 4).

At stage SRS 3, a glass slide of CEF rich in brown stains was soaked in acetic acid to induce the disappearance of the brown Von Kossa stain. (Fig. 8p,q). This strongly suggests that the staining was specific for insoluble calcium salts. The remaining localised dark dots are probably aggregates of uric acid or urate.

\section{DISCUSSION}

In the present study, we analysed the shell repair process of the Manila clam by using 3 different analytical tools: confocal Raman microspectrometry, SEM and staining of hemocytes for insoluble calcium salts. Raman microspectrometry confirmed that nonBRD- affected shells were fully made of aragonite, the metastable polymorph of calcium carbonate (Kontoyannis \& Vagenas 2000, Carteret et al. 2009), which is not surprising: earlier studies revealed that the 2 layers that make up the Manila clam shell, i.e. the outer composite prismatic layer and the inner homogeneous one, are aragonitic (Taylor et al. 1973). More interesting is that aragonite - and only aragonite — was found also in the repair zone, above the brown ring, which is fully organic and does not contain any mineral. Nor did we detect traces of vaterite or calcite. Earlier publications on molluscan shell repair indicate that, in some particular cases, aragonite was sometimes replaced by calcite or by vaterite (Muzii et al. 1966, Saleuddin \& Wilbur 1969, Saleuddin 1971, Meenakshi et al. 1975, Blackwelder \& Watabe 1977, Suzuki 1979). Another contribution of Raman microspectrometry was the identification of a polyene pigment signature, characterised by 16 bands from 1018 to $4071 \mathrm{~cm}^{-1}$ (Hedegaard et al. 2006). Polyenes were found in both layers of nonBRD-affected shells, as well as in the repaired zone, but they were virtually absent from the brown ring deposit or their presence was masked by the high luminescence of that layer. Polyenes are polyunsaturated long carbon chains of the alkene type, i.e. they exhibit 8 to 13 sequences of alternating double and single carbon-carbon bonds (16 to 26 carbon atoms) with terminal $-\mathrm{CH}_{3}$ groups (Hedegaard et al. 2006). To our knowledge, this is the first report of the presence of polyenes in the shell of the Manila clam. In earlier work, carotenoids were identified in molluscan shells with Raman spectrometry (Zhang et al. 2001, Withnall et al. 2003, Brink \& Van Der Berg 2005), and Hedegaard et al. (2006) mentioned the presence of polyenes in molluscan shells. These polyenes are the pigments responsible for the shell colour such as purple, brown or yellow of the inner and outer layers of clams. Another contribution of the Raman analysis is the detection of an intense luminescence, particularly in the outer layers of adults and juveniles, and the inner layers of juveniles. This luminescence may be due to several organic compounds: those carrying chromophores or fluorescent groups (Bell et al. 2002), organics with amide I groups (Schachar \& Solin 1975) or cellulose and lignins in Permian fossil wood (Witke et al. 2004). In bivalves, a high luminescence was recorded in the shell nacre nucleus of Pinctada margarifera (Rousseau et al. 2005). In the outer layer, the luminescence might be caused by the presence of the pigmentation or by the occurrence of organic components, which are specific to the composite prismatic layer. The last point refers to the high intensity of the luminescence in the inner layer of juvenile specimens in comparison with adults. This may suggest that the ratio of organic matrix to calcium carbonate would be higher in juvenile shells than in those of adults. 
H
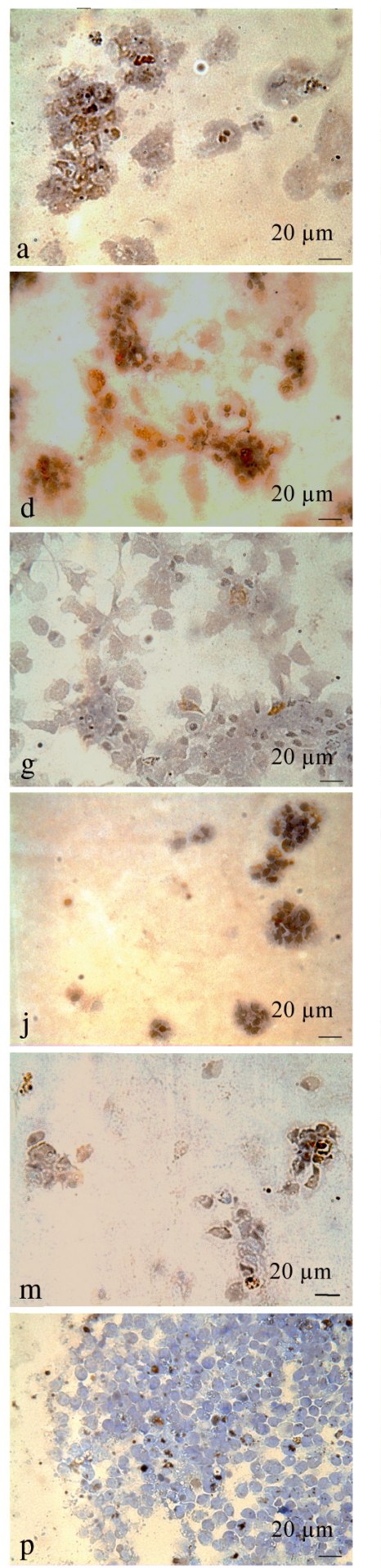

$\mathrm{CEF}$
CEF
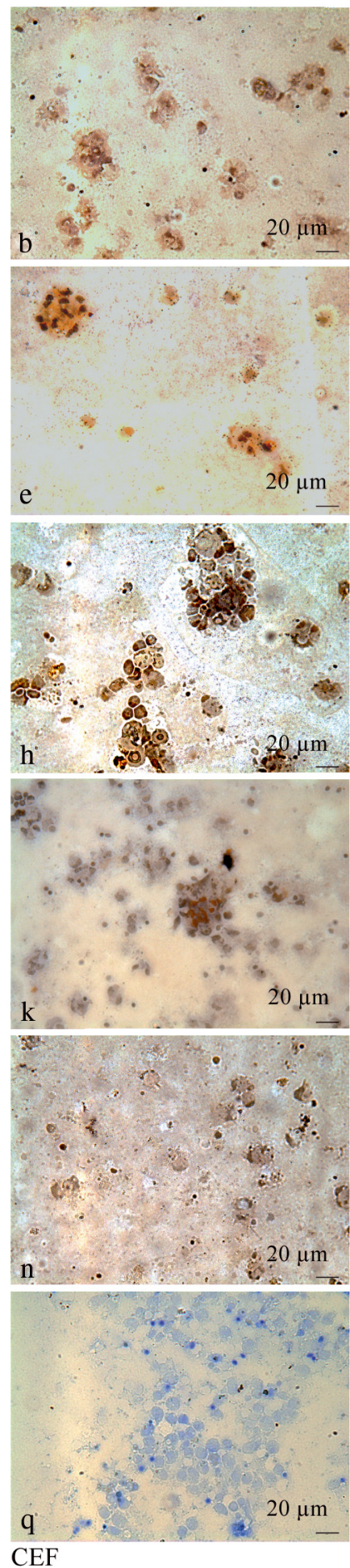

PEF
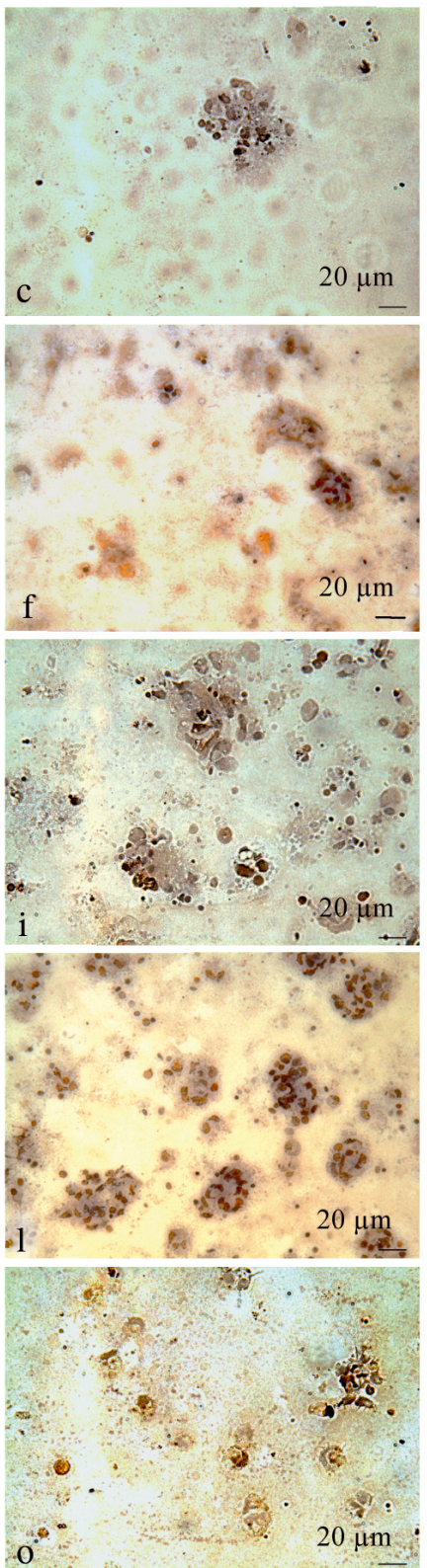

Fig. 8. Venerupis philippinarum. Examples of clam hemocytes coloured with Von Kossa stain, observed by optical microscopy, 400x. The insoluble calcium carbonate salts are dark (brown) coloured. Hemocytes from different fluids of nonBRD-affected and experimentally diseased clams were coloured to show the transport of insoluble calcium carbonate salts during the shell repair mechanism. (a-c) One nonBRD-affected sample. (d-f) One sample at SRS 1. (g-i) One sample at SRS 2. (j-1) One sample at SRS 2.5. $(\mathrm{m}-\mathrm{o})$ Two samples at SRS 3. $(\mathrm{p}, \mathrm{q})$ Two samples at SRS 3, previously soaked in $(\mathrm{p})$ water or $(\mathrm{q})$ acetic acid. H: hemolymph; CEF: central extrapallial fluid; PEF: peripheral extrapallial fluid 
Table 4. Venerupis philippinarum. Example of individual qualitative evaluation (Low $<$ Moderate $<$ Medium $<$ High $<$ Very high) of the brown colour intensity and the proportion of stained hemocytes of adult clam fluids at different shell repair stages (SRS) after Von Kossa staining. H: Hemolymph; CEF: central extrapallial fluid; PEF: peripheral extrapallial fluid

\begin{tabular}{|c|c|c|c|c|c|c|}
\hline & \multicolumn{2}{|c|}{ Hemolymph } & \multicolumn{2}{|c|}{$\mathrm{CEF}$} & \multicolumn{2}{|r|}{ PEF } \\
\hline & $\begin{array}{l}\text { Staining } \\
\text { intensity }\end{array}$ & $\begin{array}{l}\text { Proportion of } \\
\text { stained hemocytes }\end{array}$ & $\begin{array}{l}\text { Staining } \\
\text { intensity }\end{array}$ & $\begin{array}{c}\text { Proportion of } \\
\text { stained hemocytes }\end{array}$ & $\begin{array}{l}\text { Staining } \\
\text { intensity }\end{array}$ & $\begin{array}{c}\text { Proportion of } \\
\text { stained hemocytes }\end{array}$ \\
\hline NonBRD-affected & Medium & Moderate & Moderate & Medium & Medium & Medium \\
\hline Repaired specimens & & & & & & \\
\hline SRS 1 & Medium & Medium & Medium & Medium & Medium & Medium \\
\hline SRS 2 & Low & Low & Very high & Very high & Very high & Very high \\
\hline SRS 2.5 & High & High & High & Very high & High & Very high \\
\hline SRS 3 & Medium & Moderate & High & High & High & High \\
\hline
\end{tabular}

In 1992 and 1993, the periostracum of nonBRDaffected Manila clams was described and shown to resemble the organic layer of the shell repair (Paillard 1992, Paillard \& Le Pennec 1993). Furthermore, Paillard et al. (1994) formulated the hypothesis that during a BRD infection, bacteria attach to the periostracum and cause it to deteriorate. Consequently, it became brown and biomineralisation stopped, thereby initiating the beginning of the brown deposit formation (Paillard et al. 1994, Paillard \& Maes 1995a,b, Trinkler et al. 2010a). To recover after this deterioration, clams would need to synthesize a new periostracum.

Another case in point is the microstructure of the repaired versus nonBRD-affected layer. As previously noted, the shell microstructure of the Manila clam is made of a composite prismatic outer layer and a homogeneous inner layer. In earlier work, the outer layer is characterised by bundles of prisms (15 to $20 \mu \mathrm{m}$ diameter) that develop parallel to the inner and outer borders of the shell and diverge in a fan-like manner. Each individual prism is composed of minute acicular crystals (0.3 $\mu \mathrm{m}$ width) arranged in a feathery manner in radial and tangential sections. The homogeneous layer is made of aggregates of granular crystals (1 to $3 \mu \mathrm{m}$ ) without any preferential direction; from time to time, this layer is divided in sublayers where granular crystals are replaced by acicular crystals. These sublayers are arranged in 'chevron' patterns, reminiscent of a fine-crossed lamellar microstructure (Shimamoto 1986). In our study, the surface of the internal layer was characterised by organized, flattened and imbricate crystals covered by a thin organic layer, while the outer layer formed 'mounds'. This structure was typical of the composite prismatic layer when observed in transverse view. In the repair zone, the microstructures presented a greater variability. The formed crystals of the repair layer exhibited 3 shapes: rounded spheruliticlike, quadrangular and elongated. Spherulits and/or polygonal units of crystals, such as those in the composite prismatic layer, have been observed in shell repairs of Oncomelania formosa (Davis 1964), Murex fulvescens (Muzii et al. 1966), Pomacea paludosa (Blackwelder \& Watabe 1977, Watabe \& Blackwelder 1980), Helix pomatia (Abolins-Krogis 1963) and Nautilus macrophalus (Meenakshi et al. 1975). The broader variability of the microstructures observed in the repair zone clearly suggests that the cells - mantle tissue cells or hemocytes - that produce the repair layer do not have a consistent function during the repair process. Another hypothesis postulates that the mantle responsible for the mineral deposition in the repair zone is moving, i.e. it sometimes withdraws from around the repair zone. A similar phenomenon has been recently observed in the abalone Haliotis tuberculata (Fleury et al. 2008). A complex functioning of the mantle can also be inferred from the analyses of the organic matrix. Previous publications (Trinkler et al. 2009, 2010a) showed that the matrix associated with the repair zone was more abundant than the one associated with the homogeneous, nonBRD-affected layer. The 'repair' matrix contains luminescent and sulfated components.

The present study supports the suggestion that hemocytes play a key role during the shell repair process. We particularly emphasise their active contribution to the transport of insoluble calcium carbonate salts to the site of mineralisation. Our study corroborates that of Allam (1998), performed on the same species, in which holes were drilled in Manila clam shells and sealed with pieces of sterile coverslip glass. A few days after inoculation of Vibrio tapetis in the tested specimens, hemocytes were detected on the coverslips.

If hemocytes are unquestionably involved in cellular responses following shell alteration, they also may have multiple functions, depending on the mollusc model and on the characteristics of the shell injury. For example, in the freshwater snail Pomacea paludosa, $3 \mathrm{~d}$ after shell removal, hemocytes were detected in the extrapallial space (Watabe \& Blackwelder 1980). They eventually aggregated with other cell fragments to form a cellular barrier, which contributed to the deposition of a new mineral phase $7 \mathrm{~d}$ 
after shell removal. During this shell repair process, calcium was mostly localised in the intercellular space and hemocytes did not show a higher calcium concentration than that for epithelial cells. The edible mussel Mytilus edulis represents a second example of another role played by hemocytes: after periostracum damage, hemocytes migrated through the epithelium to take part in the production of the regenerated periostracum (Dunachie 1963). In the freshwater bivalve Anodonta grandis, after shell damage, hemocytes accumulated in the thickness of the altered mantle, where they were presumably responsible for regenerating the injured part of the mantle (Saleuddin 1967). Finally, in Crassostrea virginica affected by juvenile oyster disease (JOD), a disease characterised by a brown deposit of conchiolin on the inner layer of valves similar to $\mathrm{BRD}$, hemocytes were observed on the conchiolin deposit and in the altered mantle by histology (Bricelj et al. 1992, Ford \& Borrero 2001). These 4 examples clearly show that hemocytes, although similarly localised in the subepithelial region of the repairing mantle, play different roles in addition to the transport of the mineral material.

In the present study, we were not able to demonstrate whether the calcium carbonate particles transported by hemocytes were amorphous or crystalline. This question is currently debated. Previous work has found support for the existence of calcium carbonate granules in calcifying molluscan mantle tissues (Roinel et al. 1973), either intracellularly (Fournié \& Chétail 1982) or extracellularly (Istin \& Masoni 1973). In most cases, although no precise studies were done on their structure, these granules were assumed to be amorphous; because they have a greater solubility than their crystalline counterparts, amorphous calcium carbonate minerals represent a source of calcium which is rapidly available and easily remodeled. However, one recent example diverges from this pattern: in the eastern oyster Crassostrea virginica, Mount et al. (2004) demonstrated that refractive granulocytes, a subclass of hemocytes, contained calcium carbonate in a crystalline form. A combination of SEM observations and Raman spectrometry measurements showed that these crystals appeared with sharply defined edges and were calcitic. These crystals were directly brought and released at the mineralisation site by granulocytes. So far, it is not known whether the Crassostrea virginica model is the exception or the rule (Mount et al. 2004).

Numerous studies have described how the total hemocyte counts in Manila clam hemolymph increase during the first days of BRD infection, then decrease, whereas the total hemocyte count in extrapallial fluids always increases. This trend was explained as a mobilisation of hemocytes to the extrapallial fluids (Allam et al. 2000a,b). Hemocytes are also observed in the
Manila clam mantle, which is altered by Vibrio tapetis during a BRD infection (Allam et al. 2002). However, none of these studies examined the link with shell repair. One study also examined the correlation between hemocytes and resistance to BRD, but did not link it to shell repair: Allam et al. (2001) observed that different populations of Venerupis philippinarum (from France and the USA) and Ruditapes decussatus (from France) did not exhibit the same capability to overcome BRD; greater resistance was associated with a higher concentration of granular hemocytes and greater phagocytic activity.

If these observations are confirmed, we can then seriously envisage the selection of BRD-resistant stocks of Manila clams by sampling their hemocytes. However, additional work on the cell typology of the Manila clam immune system, combined with the identification of molecular markers of hemocyte types using a proteomics approach, appear to be an essential prerequisite.

Acknowledgements. We thank A. Lemercier and N. Le Goïc for technical assistance, S. Ford for manuscript corrections, Satmar (France) for the production of juvenile clams and their help on clam deployment and the ANR Multistress Project for financing. The contribution of F.M. is supported by the ANR grant ACCRO-Earth (ref. BLAN06-2_159971, coordinator G. Ramstein).

\section{LITERATURE CITED}

Abolins-Krogis A (1963) The morphological and chemical basis of the initiation of calcification in the regenerating shell of Helix pomatia (L.). Acta Univ Ups 20:5-22

Allam B (1998) Rôle des fluides extrapalléaux des bivalves dans la défense immunitaire. Cas de la maladie de l'anneau brun chez la palourde d'élevage, Ruditapes philippinarum. Université de Bretagne Occidentale, Brest

Allam B, Paillard C (1998) Defense factors in clam extrapallial fluids. Dis Aquat Org 33:123-128

Allam B, Paillard C, Auffret M (2000a) Alterations in hemolymph and extrapallial fluid parameters in the Manila clam, Ruditapes philippinarum, challenged with the pathogen Vibrio tapetis. J Invertebr Pathol 76:63-69

> Allam B, Paillard C, Howard A, Le Pennec M (2000b) Isolation of the pathogen Vibrio tapetis and defense parameters in brown ring diseased Manila clams Ruditapes philippinarum cultivated in England. Dis Aquat Org 41:105-113

Allam B, Ashton-Alcox KA, Ford SE (2001) Haemocyte parameters associated with resistance to brown ring disease in Ruditapes spp. clams. Dev Comp Immunol 25:365-375

Allam B, Paillard C, Ford SE (2002) Pathogenicity of Vibrio tapetis, the etiological agent of brown ring disease in clams. Dis Aquat Org 48:221-231

Bell SEJ, Bourguignon ESO, Grady AO, Villaumie J, Dennis AC (2002) Extracting Raman spectra from highly fluorescent samples with 'scissors' (SSRS, shifted-substracted Raman spectroscopy). Spectrosc Eur 14:17-20

Blackwelder PL, Watabe N (1977) Studies on shell regeneration. II. The fine structure of normal and regenerated shell of the freshwater snail Pomacea paludosa. Biomineralization 9:1-10 
Boggild OB (1930) The shell structure of the mollusks, Vol 2. Mémoire de l'Académie Royale des Sciences et des Lettres de Danemark, 9ème série, Copenhagen

Bricelj VM, Ford SE, Borrero FJ, Perkins FO and others (1992) Unexplained mortalities of hatchery-reared, juveniles oysters, Crassostrea virginica (Gmelin). J Shellfish Res 11: 331-347

Brink DJ, Van Der Berg NG (2005) An investigation of green iridescence on the mollusc Patella granatina. J Phys D Appl Phys 38:338-343

Carriker MR (1996) The shell and ligament. In: Kennedy VS, Newell RIE, Eble AE (eds) The eastern oyster Crassostrea virginica. Maryland Sea Grant, College Park, MD

- Carteret C, Dandeu A, Moussaoui S, Muhr H, Humbert B, Plasari E (2009) Polymorphism studied by lattice phonon Raman spectroscopy and statistical mixture analysis method. Application to calcium carbonate polymporphs during batch crystallization. Cryst Growth Des 9:807-812

Davis GM (1964) Shell regeneration in Oncomelania formasana (Gasteropoda: Hydrobiidae). Malacologia 2: 145-159

Dunachie JF (1963) The periostracum of Mytilus edulis. Trans R Soc Edinb 65:383-411

Flassch JP, Barret J, Mazurie J, Maes P and others (1992) L'élevage de la palourde, programme national de recherche sur la maladie de l'anneau brun. In: Les mollusques marins: biologie et aquaculture, Brest, 9 Nov 1990. Ifremer, Brest, p 127-140. Available at: http://archimer.ifremer.fr/doc/ 1992/acte-925.pdf

Fleury C, Marin F, Marie B, Luquet G and others (2008) Shell repair process in the green ormer Haliotis tuberculata: a histological and microstructural study. Tissue Cell 40: 207-218

Ford SE, Borrero FJ (2001) Epizootiology and pathology of juvenile oyster disease in the Eastern oyster, Crassostrea virginica. J Invertebr Pathol 78:141-154

Fournié J, Chétail M (1982) Accumulation calcique au niveau cellulaire chez les mollusques. Proc 7th Int Malacol Congr, Colloque Calcium et Structures Squelettiques. Malacologia 22:265-284

Gabe M (1968) Techniques histologiques. Masson \& Cie, Paris

Gosling E (2003) Bivalve molluscs. Biology, ecology and culture. Blackwell Science, Oxford

> Hedegaard C, Bardeau JF, Chateigner D (2006) Molluscan shell pigments: an in situ resonance Raman study. J Molluscan Stud 72:157-162

Istin M, Masoni A (1973) Absorption et redistribution du calcium dans le manteau des lamellibranches en relation avec la structure. Calcif Tissue Res 11:151-162

Kontoyannis CG, Vagenas NV (2000) Calcium carbonate phase analysis using XRD and FT-Raman spectroscopy. Analyst 125:251-255

Meenakshi VR, Blackwelder PL, Hare PE, Wilbur KM, Watabe N (1975) Studies on shell regeneration. I. Matrix and mineral composition of the normal and regenerated shell of Pomacea paludosa. Comp Biochem Physiol A Physiol 50:347-351

Mount AS, Wheeler AP, Paradkar RP, Snider D (2004) Hemocyte-mediated shell mineralization in the eastern oyster. Science 304:297-300

Muzii EO, Catherine H, Skinner W (1966) Calcite deposition during shell repair by the aragonitic gasteropod Murex fulvescens. Science 151:201-203

Nakahara H, Bevelander G, Kakei M (1982) Electron microscopic and amino acid studies on the outer and inner shell layers of Haliotis rufescens. Venus 41:33-46

> Oubella R, Maes P, Paillard C, Auffret M (1993) Experimentally induced variation in hemocyte density for Ruditapes philippinarum and Ruditapes decussatus (Mollusca, Bivalvia). Dis Aquat Org 15:193-197

Paillard C (1992) Etiologie et caractérisation de la maladie de l'anneau brun chez la palourde d'élevage, Ruditapes philippinarum. Doctorat d'université, Université de Bretagne Occidentale, Brest

> Paillard C (2004) A short-review of brown ring disease, a vibriosis affecting clams, Ruditapes philippinarum and Ruditapes decussatus. Aquat Living Resour 17:467-475

Paillard C, Le Pennec M (1993) Ultrastructural studies of the mantle and the periostracal lamina in the Manila clam, Ruditapes philippinarum. Tissue Cell 25:183-194

Paillard C, Maes P (1990) Etiology of the brown ring disease in Tapes philippinarum: pathogenicity of a Vibrio sp. C R Acad Sci Paris 310:15-20

Paillard C, Maes P (1994) Brown ring disease in the Manila clam Ruditapes philippinarum: establishment of a classification system. Dis Aquat Org 19:137-146

Paillard C, Maes P (1995a) The brown ring disease in the Manila clam, Ruditapes philippinarum. I. Ultrastructural alterations of the periostracal lamina. J Invertebr Pathol 65:91-100

Paillard C, Maes P (1995b) The brown ring disease in the Manila clam, Ruditapes philippinarum. II. Microscopic study of the brown ring syndrome. J Invertebr Pathol 65: $101-110$

Paillard C, Percelay L, Le Pennec M, Le Picard D (1989) Origine pathogene de l'anneau brun' chez Tapes philippinarum (Mollusque, Bivalve). C R Acad Sci Paris 309: 235-241

Paillard C, Maes P, Oubella R (1994) Brown ring disease in clams. Annu Rev Fish Dis 4:219-240

Paillard C, Gausson S, Nicolas JL, Le Pennec JP, Haras D (2006) Molecular identification of Vibrio tapetis, the causative agent of the brown ring disease of Venerupis philippinarum. Aquaculture 253:25-38

Querne J (2005) Suivi de trois familles de Ruditapes philippinarum et évaluation de leur résistance à la maladie de l'anneau brun. Stage de master 1, Université de Bretagne Occidentale, Brest

Roinel N, Morel F, Istin M (1973) Etude des granules calcifiés du manteau des lamellibranches à l'aide de la microsonde électronique. Calcif Tissue Res 11:163-170

Rousseau M, Lopez E, Couté A, Mascarel G, Smith DC, Naslain R, Bourrat X (2005) Sheet nacre growth mechanism: a Voronoi model. J Struct Biol 149:149-157

Saleuddin ASM (1967) The histochemistry of the mantle during the early stage of shell repair. Proc Malacol Soc Lond $37: 371-380$

Saleuddin ASM (1971) Fine structure of normal and regenerated shell of Helix. Can J Zool 49:37-41

Saleuddin ASM, Wilbur KM (1969) Shell regeneration in Helix pomatia. Can J Zool 47:51-53

Schachar RA, Solin SA (1975) The microscopic protein structure of the lens with a theory for cataract formation as determined by Raman spectroscopy of intact bovine lenses. Investig Ophthalmol 14:380-396

Shimamoto M (1986) Shell microstructure of the Veneridae (Bivalvia) and its phylogenetic implications. Tohoku Univ Sci Rep Ser 2 56:1-39

Simkiss K, Wilbur KM (1989) Biomineralization, cell biology and mineral deposition. Academic Press, San Diego, CA

Spann N, Harper EM, Aldridge DC (2010) The unusual mineral vaterite in shells of the freshwater bivalve Corbicula fluminea from the UK. Naturwissenschaften 97: $743-751$ 
Suzuki S (1979) Mineralization of the regenerated organic membrane-shell in Mytilus edulis (Pelecypoda). J Ceol Soc Jpn 85:669-677

Taylor JD, Kennedy WJ, Hall A (1973) The shell structure and mineralogy of the Bivalvia, II. Lucinacea-Clavagellacea. Conclusions. Bull Br Mus (Nat Hist) Zool 22:253-294

Trinkler N, Marin F, Guichard N, Labonne M, Bardeau JF, Paillard C (2009) Shell repair in the clam Ruditapes philippinarum, affected by the Brown Ring Disease (BRD): a biochemical and serological study. Mater Res Soc Symp Proc 1187:89-94

Trinkler N, Labonne M, Marin F, Jolivet A and others (2010a) Ruditapes phillipinarum shell repair face front to the Brown Ring Disease: a follow-up of the organic matrix using Raman spectroscopy and WDS microprobe. Anal Bioanal Chem 396:555-567

Trinkler N, Sinquin G, Querne J, Paillard C (2010b) Resistance to Brown Ring Disease in the Manila clam, Ruditapes philippinarum: a study of selected stocks showing a recovery process by shell repair. J Invertebr Pathol 104: $8-16$

Editorial responsibility: Mike Hine, Fouras, France
Urmos J, Sharma SK, Mackenzie FT (1991) Characterization of some biogenic carbonates with Raman spectroscopy. Am Mineral 76:641-646

Watabe N, Blackwelder PL (1980) Ultrastructure and calcium localization in the mantle epithelium of the freshwater gasteropod Pomacia paludosa during shell regeneration. In: Omori M, Watabe N (eds) The mechanisms of biomineralisation in animals and plants. Tokai University Press, Tokyo, p 131-144

Withnall R, Chowdhry BZ, Silver J, Edwards HG, de Oliveira LFC (2003) Raman spectra of carotenoids in natural products. Spectrochimica Acta A Mol Biomol Spectrosc 59:2207-2212

Witke K, Gotze J, Rossler R, Dietrich D, Marx G (2004) Raman and cathodoluminescence spectroscopic investigations on Permian fossil wood from Chemnitz - a contribution to the study of the permineralisation process. Spectrochim Acta A Mol Biomol Spectrosc 60:2903-2912

Zhang G, Xie X, Wang Y (2001) Raman spectra of nacre from shells of main pearl-culturing mollusks in China. Guang Pu Xue Yu Guang Pu Fen Xi 21:193-196

Submitted: March 17, 2010; Accepted: September 17, 2010 Proofs received from author(s): January 10, 2011 